\title{
Jawlensky en el sendero de la meditación
}

\author{
Francesco GIAVERI \\ Departamento de Historia del Arte III \\ Universidad Complutense de Madrid \\ francescogiaveri@gmail.com
}

Entregado: $25 / 01 / 2013$

Aceptado: 04/07/2013

\section{RESUMEN}

La más amplia de las series de Alexej von Jawlensky, las Meditaciones, se centra en la representación del rostro humano. Una secuencia de variaciones realizada con voluntad febril. Excluyendo todos los caracteres de la identidad individual, pretende abrazar lo universal y, aún más, lo trascendental; para lograrlo recurre a la serialidad, su estrategia. Jawlensky realiza esta serie entre 1934 y 1938, en arduas condiciones, tanto económicas como físicas. Estos modernos iconos afloran de un proceso de extrema introspección, un estado de catarsis y concentración en el que eleva estas oraciones a Dios, depuradas de todo lo innecesario para centrase en una meditación extática. Aspiran a sobrepasar la urgencia de lo inmediato, alcanzar una dimensión más profunda para ahuyentar el miedo del tiempo despojado de su necesidad eterna.

Palabras clave: Jawlensky; serialidad; meditación; retrato; expresionismo.

\section{Jawlensky on the meditation's path}

\begin{abstract}
The most significative of Jawlensky's last series, the Meditations, represent high point of stylization and control of colour. From 1934 to 1937, the artist painted several of these modern icons in a very difficult situation, both economically and phisically. They represent a culmination of his oeuvre and his comitment to seriality. Considered as a kind of transcendental meditation, this series of heads represents its strategy against the contingent time.
\end{abstract}

Key words: Jawlensky; seriality; meditation; portrait; expressionism. 


\section{Introducción}

La más amplia de las series de Alexej von Jawlensky, las Meditaciones, se centra en la representación del rostro humano. Una secuencia de variaciones realizada con voluntad febril. Ahondar en el misterio del paisaje facial le mueve a limitar el campo de su indagación pictórica. Reduce progresivamente sus retratos, inicialmente a la media figura, luego al primer plano, hasta centrarse en la parte frontal del óvalo. Excluyendo todos los caracteres de la identidad individual, pretende abrazar lo universal y, aún más, lo trascendental; para lograrlo recurre a la serialidad, su estrategia. "Las Meditaciones no pueden ser comparadas con ninguna otra obra de su época. En su concentración, una reforma ritual de lo espiritual, constituyen un desarrollo original y la culminación de su trayectoria" ${ }^{1}$. Jawlensky realiza esta serie entre 1934 y 1938, en arduas condiciones, tanto económicas como físicas. Consigue pintar hasta seis versiones en un sólo día, cuando la enfermedad se lo permite, cerrado en su habitación de donde ya casi no sale. Estos modernos iconos afloran de un proceso de extrema introspección, un estado de catarsis y concentración en el que eleva estas oraciones a Dios, depuradas de todo lo innecesario (propio del tiempo transitorio) para centrase en una meditación extática (donde el tiempo se para a la vez que se dilata) ${ }^{2}$. Su serie aspira a sobrepasar la urgencia de lo inmediato, alcanzar una dimensión más profunda para ahuyentar el miedo del tiempo despojado de su necesidad eterna. Advertía Nietzsche: “¿Hay algo que destruya más rápidamente que trabajar, pensar y sentir, sin una necesidad interior, sin una elección íntima y personal, sin experimentar ningún placer, como un autómata del «deber»?"3.

\section{La necesidad del aprendizaje}

En sus Memorias, describe el episodio que le convertirá en pintor en términos milagrosos: "me llevaron, en verano de 1880, a la Exposición Universal de Moscú. Para mí era todo bastante aburrido. Sin embargo, cuando llegué a la sección de arte -donde había sólo pintura, y era la primera vez que veía pinturas- mi alma se conmovió de tal forma que de Saulo me convertí en Pablo. Este fue el cambio decisivo de mi vida. A partir de aquel momento el arte se convirtió en mi ideal, lo más sagrado hacia donde anhelaba mi alma y todo mi ser"4. Atender a las voluntades de su alma y concebir el

1 J AWLENSKY, Angelica, "The Autonomy of Colour: the Evolution of Jawlensky's Art", en Alexej von Jawlensky. Catalogue Raisonné of Oil Paintings, Vol III, 1934-1937, Londres, Sotheby’s Publications,1993, p. 17

2 En 1936 Jawlensky escribe: “ $¡ O h$ Dios! Trabajo en éxtasis con los ojos en lágrimas y sigo trabajando hasta que oscurezca. Luego estoy exhausto y me quedo sentado sin moverme, casi desmayado y con tremendos dolores en las manos". JAWLENSKY BIANCONI, ANGELICA, "La raffigurazione del Dio visibile", en Alexej von Jawlensky, catálogo de la exposición (Milán, 1995), Milán, Palazzo Reale, Charta, 1995, p. 28

3 NIETZSCHE, Friedrich, El Anticristo, Madrid, Edimat, 2009, p. 39

4 JAWLENSKY, Alexej von, "Memoir dictated to Lisa Kümmel, Wiesbaden, 1937", en Alexej von Jawlensky. Catalogue Raisonné of Oil Paintings, Vol I, 1890-1914, Londres, Sotheby's Publications, 1991, p. 26 
arte como una dimensión mística es decisivo para Jawlensky ${ }^{5}$. Dicta sus Memorias en 1937 a su asistente, Lisa Kümmel, cuando la enfermedad le impide pintar. Publicadas en 1970, interesan porque revelan, entre líneas, la construcción de su identidad artística como pintor del alma.

Alexej von Jawlensky (Torsok, 1864 - Wiesbaden, 1941), vástago de una noble familia rusa, estudia en la Academia Militar en Moscú aunque consigue, en 1889, ser trasladado a San Petersburgo, donde frecuenta la prestigiosa Academia de Bellas Artes, lugar en el que conoce a Ilya Repin, uno de los pintores más destacados de la época. Convirtiéndose en su alumno, entra en contacto con un grupo de artistas consolidados. En verano de 1896 emprende un largo viaje de formación por Dresde, Colonia, Amberes, París y Londres. Experiencia que le persuade a dejar su país natal para medrar en su arte en un ambiente menos conservador. Se traslada entonces a Múnich junto con Igor Grabar, Dimitri Kardowsky y Marianne von Werefkin. Con esta última, conocida a través de Ilya Repin, anuda una relación de amistad y complicidad artística que dura hasta 1921. Además de ofrecer un contexto artístico de primer orden, en Múnich habita una nutrida comunidad rusa formada por aristócratas, ricos burgueses y exiliados políticos (Lenin transcurre ahí algunos años). Jawlensky encuentra un ambiente estimulante con Kandinsky, Gabriele Münter, Alexander Sacharoff, Wladimir Bechtejeff y Erma Barrera-Bossi, entre otros. Empieza a frecuentar la escuela de Anton Azbe, donde se le brinda una cierta liviandad respecto al hacer pictórico, una ausencia de imposiciones convencionales y un decidido rechazo a la práctica de copiar modelos establecidos, como se enseñaba en las academias. "Ver exterior y mirar interior", diría Klee ${ }^{6}$, y ésta parece ser también la convicción del artista ruso.

En 1905 expone en el Salón de Otoño de París y conoce a Matisse cuyo uso ornamental del color le causará una profunda impresión. Son años donde su estilo está en constante ebullición entre las rigurosas normas del academicismo ruso y las influencias del arte francés, desde Gauguin hacia Matisse, pasando por Cézanne, además de una no celada admiración por Van Gogh ${ }^{7}$. Escribe Jawlensky: "En la primavera de 1905 fuimos todos a Carentec, en la costa bretona. Trabajé muchísimo y entendí cómo traducir la naturaleza en colores, de acuerdo con el fuego de mi espíritu. Pinté muchos paisajes, los matorrales que veía desde la ventana y cabezas de bretones. Los cuadros ardían de color. [...] Por primera vez había comprendido cómo pintar no lo que veía, sino lo que sentía" 8 . Años ardientes, hasta inflamados por el deseo de aprender y encontrar su camino; estímulos que le arrojan hacia el color, elemento principal de sus cuadros frente a la forma. El pintor aprende que la mímesis no aporta gran cosa

\footnotetext{
5 "He vivido el arte con profundidad. Te hablaría de mi desarrollo artístico que es, a la vez, el desarrollo de mi alma”. JAWLENSKY, Alexej von, "Letter to Pater Willibrord Verkade", Alexej von Jawlensky. Catalogue Raisonné of Oil Paintings, Vol I, 1890-1914, Londres, Sotheby's Publications, 1991, p. 34

6 KLEE, Paul citado en LEINZ, GOTTLIEB, L'affermarsi della componente mistica, en CHIAPPINI, Rudy (ed.), Alexej von Jawlensky, catálogo de la exposición (Locarno, 1989), Pinacoteca Comunale Casa Rusca, Milán, Electa, 1989, p. 196. Klee anota en su diario una visita a Jawlensky y Werefkin: "los rusos eran, como siempre, gente de mucho talento", en KLEE, Paul, Diarios 1898-1918, Madrid, Alianza, 1987, p. 247

7 En 1908 Jawlensky compra, en Múnich, una pintura de Van Gogh, "La Maison du père Pilon" (1890). Tendrá que venderla en los años 20 para hacer frente a sus dificultades económicas.

8 JAWLENSKY, Alexej von (1991), op. cit., p. 30
} 
al conocimiento de lo hondo. Si el mundo ya existe, no tiene sentido replicarlo; el papel del artista consiste en sondear los movimientos profundos, ajenos a la superficie. Le interesa el proceso específico del acto pictórico, un ritual que le permite escarbar en los sobresaltos de su espíritu. Su afán místico descansa en el color. En la primera fase de su producción, las superficies planas están encarceladas en contornos precisos, simplificados y definidos a través de un trazo grueso de azul prusia. Una manera que aprende quizá de Gauguin, cuyo conocimiento Jawlensky profundiza a través del padre benedictino Willibrord Verkade, discípulo de Gauguin y Sérusier, con el que comparte taller en Múnich entre 1907 y 1908.

\section{Murnau y la Vereinigung}

En el verano de 1908 transcurre unos meses en Murnau, junto a Kandinsky, Münter y Werefkin. Gabriele Münter recuerda aquel periodo, cuando Jawlensky era técnicamente el más avanzado, con estas palabras: "disfruté particularmente de la posibilidad de enseñar mis obras a Jawlensky que las elogió profusamente y me explicó muchas cosas: me brindó la posibilidad de aprovechar su gran experiencia y me hablaba de síntesis"9. El concepto de síntesis implica un afán por reducir las formas a lo esencial, algo que, de alguna manera, reclama una práctica serial, es decir, repetir una estructura en variaciones sucesivas ${ }^{10}$.

En 1909 Jawlensky, Münter, Kandinsky y Werefkin junto a Alexander Kanoldt, Adolf Erbslöh, Oskar Wittenstein y Heinz Schnabel fundan la Neue Künstler-Vereinigung München. En un primer momento parece que Jawlensky será su presidente, aunque es evidente que el más apto a cubrir dicho cargo es Kandinsky, debido a sus experiencias anteriores con la escuela de la Phalanx, sus extensos contactos internacionales y su capacidad de promocionar las nuevas tendencias artísticas con manifiestos y exposiciones. Al grupo se unirán, entre otros, Bechtejev, Kogan, Paul Baum, Pierre Girieud, Karl Hofer, Alfred Kubin y Erma Barrera-Bossi.

Jawlensky y Kandinsky son los artistas más radicales, cuyas teorías leemos en el manifiesto de la Vereinigung: "Nuestro punto de partida es la convicción de que el artista, más allá de las impresiones que recibe de la apariencia del mundo exterior, continuamente va acumulando experiencia de su personal mundo interior. Nosotros buscamos formas artísticas capaces de expresar la permeabilidad de las experienciasformas que tienen que estar liberadas de todo lo secundario, para transmitir enérgicamente lo necesario, en breve, la síntesis artística. Esta nos parece la solución y va uniendo, en espíritu, a un número siempre mayor de artistas" ${ }^{11}$. Un texto programático donde se sostiene la superación de la observación naturalista en favor de la aten-

9 ZWEITE, Armin, The Blue Rider in the Lenbachhaus, Munich, Prestel, 1989, p. 20

10 Cuando la representación se reduce a lo esencial, cada vez más abstracta, las relaciones entre los elementos se perciben con más facilidad, algo evidente si pensamos, por ejemplo, en la pintura de Mondrian. La serialidad no hace otra cosa que enseñar el juego de estas relaciones: correspondencias, diferencias e intervalos.

11 ZWEITE, Armin (1989), op.cit., p. 25 
ción al mundo interior; crear formas libradas de lo superfluo y un uso expresivo del color. Vuelve el concepto, querido por Jawlensky, de síntesis, que deviene un axioma del grupo y será probablemente la causa de la separación de Jawlensky y Werefkin de las instancias sucesivamente avanzadas por Kandinsky. La aparición del término se remonta a la exposición de 1890 del Groupe Impressioniste et Synthésiste; luego Gauguin clamará $¡$ Viva la síntesis! ${ }^{12}$. Se trata de una idea muy difusa en la época y diversamente interpretada; significa tanto una estilización progresiva como la búsqueda de un equilibrio entre forma y contenido y, en el caso de Jawlensky, entre lo terrenal y lo trascendental.

Mientras Jawlensky busca conciliar las impresiones del mundo externo con la emoción subjetiva, Kandinsky radicaliza la oposición entre lo material y lo espiritual. En el texto que acompaña la segunda exposición de la Vereinigung lo expresará con su célebre y misterioso "hablar del oculto por medio del oculto" ${ }^{3}$. Si Jawlensky y Werefkin se disocian del grupo es porque se hace patente la voluntad de Kandinsky de sobrepasar la idea de síntesis y propugnar la total eliminación de elementos representativos. Jawlensky se opone a despedirse de cualquier referencia al mundo exterior y recurrirá a ella como indicador de ruegos trascendentales, por medio de la repetición sistemática.

Los parpadeos del espíritu difícilmente pueden encarcelarse en una sola obra, como los espectros se desvanecen para reaparecer en otro lado. El artista escribe que "manzanas, árboles, rostros humanos, son para mí sólo indicios para ver en ellos algo distinto: la vida del color que percibe un apasionado, un enamorado" ${ }^{14}$. Sentimientos que reclaman una incesante renovación del deseo de trascendencia, su ansia de Dios. Jawlensky se abandona así a la repetición de rostros, paisajes y bodegones, pero sobre todo rostros. Quizá porque es la cara del otro la que nos impide matar, como propone Levinas, es ahí donde nos reconocemos al mismo tiempo uno y miles. Jawlensky no renuncia nunca a la otredad que le ofrece el mundo; es un arranque para alcanzar una dimensión universalmente compartida, aunque desconocida ${ }^{15}$. El esquema del rostro humano, reducido a una cruz en las Meditaciones, da cabida a infinitas variaciones de color. En términos nada místicos (aunque sí extáticos) y por eso mismo más sugerentes en este contexto, escribe Juan José Lahuerta: "Manifestación de la carne, la cruz es el lugar de la repetición eterna del consumo extático, donde se niega la experiencia y se afirma la infinita repetición de lo mismo, y también el lugar de la gran exposición que, como el escaparate, hace de lo siempre igual lo siempre nuevo" ${ }^{16}$. Nuestro pintor

12 ZWEITE, Armin (1989), op.cit., p. 25

13 Ibid., p. 28

14 JAWLENSKY, Alexej von, citado en JAWLENSKY, Angelica, “Alexej von Jawlensky: un maestro del color", Alexej von Jawlensky, catálogo de la exposición (Madrid, 1992), Madrid, Fundación Juan March, 1992, p. 11

15 Anton Schnack reseñando una exposición de Jawlensky en 1921-22, elogia la espiritualidad de su pintura y a propósito del rostro escribe: "Para él, el mundo es un rostro. Para él, el rostro es un paisaje donde sumergirse, representándolo con todo el fuego de su alma, sus secretos, su melancolía y su dandismo". SCHNACK, Anton, citado en BELGIN, Tayfun, Alexej von Jawlensky. A biography, San Petersburgo, The State Russian Museum, Palace Editions, 2000, p. 162

16 LAHUERTA, Juan José, El fenómeno del éxtasis, Madrid, Siruela, 2004, pp. 169-170 
se empeñará en desviar la atención del consumo material y a reconducirlo, a través de experiencias sensoriales y pictóricas, por el camino de la trascendencia espiritual.

"Las obras estaban perfiladas fuertemente de azul prusia y tenían un tremendo poder de éxtasis interior" "17 así Jawlensky describe sus pinturas de antes de la guerra. Del éxtasis del consumo a las reverberaciones del espíritu, el artista ahonda en el reino inalienable del alma. Un acercamiento a lo trascendental que, si bien es cierto que durante la meditación supone la suspensión del ejercicio de los sentidos, se alcanza mismamente inflamándolos de manera reiterativa. A través de los sentidos, el alma. ¿El éxtasis místico de los derviches turcos o de los monjes budistas no se logra justamente por medio del sonido repetido y de gestos estrictamente regulados?

\section{Series antecedentes. El paisaje}

En 1914 comienza el conflicto que será destructor tanto de rostros como de almas ${ }^{18}$. Poco después del estallido de la guerra, todos los rusos se ven obligados a dejar Alemania en un plazo de cuarenta y ocho horas. La huida le obliga a separarse del entorno cultural en el que vive. Kandinsky vuelve a Rusia, mientras Jawlensky repara en Suiza, a St. Prex, dejando atrás a Gabriele Münter, Paul Klee, Franz Marc, August Macke y Adolf Erbslöh, entre muchos otros.

En St. Prex, un pequeño pueblo junto al lago de Ginebra, alquila una modesta casa pero no consigue un estudio donde pintar a gusto. En este periodo, empieza a manifestarse una primera instancia serial, cuando Jawlensky mira por la ventana de su nuevo hogar, después de la precipitada huida. Relata el artista: "Nuestra casa era muy pequeña y yo no tenía una habitación exclusivamente para mí; tan sólo podía considerar mía una ventana. Pero mi alma era tan oscura e infeliz a causa de aquellas espantosas experiencias, que me sentía afortunado de poder quedarme tranquilamente sentado ante la ventana y abstraerme con mis sentimientos y pensamientos. [...] En un primer momento quise seguir pintando en St. Prex como lo hacía en Múnich, pero algo en mi interior me impedía seguir pintando cuadros tan coloreados y sensuales. Mi alma había cambiado a causa de los dolorosos sufrimientos y esto me llevaba a buscar otras formas y colores para poder expresar lo que mi alma sentía" ${ }^{19}$. Emprende así las Variaciones, el origen de su serialidad ${ }^{20}$. El tamaño de los cuadros se va uniformando a la vez que la limitación de las formas, que Jawlensky se auto-impone, permite enfrentarse a las inagotables posibilidades del color. Desde la única parte del hogar donde aislarse y reflexionar, se dedica a reproducir el paisaje que tiene en frente. "El camino, madre de todas las variaciones", pintado en otoño de 1914, muestra

17 JAWLENSKY, Alexej von (1991), op. cit., p. 31

18 DIDI-HUBERMAN, Georges, Atlas ¿Cómo llevar el mundo a cuesta?, catálogo de la exposición (Madrid, 2011), Madrid, MNCARS, 2011, p. 150

19 JAWLENSKY, Alexej von (1991), op. cit., p. 32

20 John Coplans reconoce en las Variaciones de 1914 el comienzo de la obsesión del pintor por las formas seriales, cuyo impulso original, psíquico, no es posible hallar. Estas páginas lo intentan. COPLANS, John, “Alexej Jawlensky", Serial Imagery, catálogo de la exposición (Pasadena, Seattle, Santa Barbara, 1968-69), Pasadena, Pasadena Art Museum, 1968, p. 31 
aquella porción de terreno: un sendero, un gran abeto blanco a la izquierda, árboles y matorrales, algunas casas, a lo lejos se intuye la presencia del lago y de los montes al otro lado de la orilla. Jawlensky tiene de pronto conciencia de haber encontrado la ur-form, de donde comenzar a repetir el acto pictórico en incontables ejemplares. "El sujeto es, precisamente, la variación sobre un tema y no el paisaje. Las formas se han separado de su valor real, se han independizado, transformándose en una metáfora de la naturaleza. El paisaje llega a ser su interpretación, una reproducción abstracta de la naturaleza en la que, sin embargo, está intensamente representado el estado emocional del artista" ${ }^{21}$. Después de que se marche de St. Prex, seguirá pintando esta serie. Realizará más de 300 Variaciones, cambiando ligeramente la composición. Lo que comienza como un paisaje se va simplificando, por estilizaciones sucesivas, hasta arribar a una interpretación totalmente interiorizada. "Empecé a pintar algo para expresar a través de los colores lo que la naturaleza me sugería. Con arduo trabajo y grandísima concentración iba encontrando poco a poco los colores y las formas para expresar lo que mi Yo espiritual exigía. Todos los días pintaba estas Variaciones de color, inspirado siempre por las circunstancias de la naturaleza y de mi espíritu"22. Jawlensky cubre la realidad con un manto sobrenatural y una mirada religiosa.

La serie de las Variaciones termina en 1921 por haber llegado a la imposibilidad de ulteriores evoluciones plásticas en el tema tratado. Constituye el puente entre las pinturas cargadas de sensualidad de antes de la guerra y aquellas más místicas y concentradas en el rostro que convierte, desde entonces, en el leitmotiv de su producción ${ }^{23}$. El rostro encarna el misterio de la existencia. "El estudio del rostro, de lo particular reconocido como lugar de encuentro con lo universal" ${ }^{24}$. El óvalo cósmico es el campo de batalla de las emociones y del tiempo que trascurre imprimiendo sus huellas, como surcos en el campo. "Honra el rostro del anciano", recomienda el libro del Levítico ${ }^{25}$.

\section{Aislamiento}

Después de la huida, Jawlensky vivirá alejado de la escena artística internacional. Sin embargo, en St. Prex recibe la visita inesperada de una admiradora, Emmy Scheyer. Esta joven y adinerada artista alemana había visto, en 1915, una obra de Jawlensky, "La chepa I", en ocasión de una exposición de artistas rusos. Le genera tanta impresión que decide ir a conocerle y abandonar su carrera artística para dedicarse exclu-

21 JAWLENSKY, Angelica, “Alexej von Jawlensky: un maestro del color”, Alexej von Jawlensky, catálogo de la exposición (Madrid, 1992), Madrid, Fundación Juan March, 1992, p. 16

22 JAWLENSKY, Alexej von (1991), op. cit., p. 32

23 MEYERS, Bernard S., "Alexei von Jawlensky. An Expressionist Currently in the Limelight", en College Art Journal, 16:3, 1957, p. 216

24 BONNEFOY, Yves, "Observaciones sobre el retrato", en BONNEFOY, Yves, La nube roja, Madrid, Síntesis, 2003, p. 156

25 Levítico $(19,32)$ 
sivamente a promocionar la obra de Jawlensky. Con suerte alterna ${ }^{26}$, pero siempre con incansable dedicación, organiza exposiciones en Alemania y Estados Unidos ${ }^{27}$. A partir de 1925, Galka ${ }^{28}$ Scheyer gestiona las exposiciones de los "Cuatros Azules": Klee, Kandinsky, Feininger y Jawlensky. No es un grupo ni una asociación oficial, se trata más bien de amistad ${ }^{29}$ y estrategia comercial. El gran número de intercambios de obras entre los artistas evidencia una apreciación recíproca ${ }^{30}$. La iniciativa pretende buscar compradores en Estados Unidos para hacer frente a la nefasta situación económica europea. Por otro lado, quieren ayudar a Jawlensky que, de los cuatros, se encuentra en la situación económica más complicada. Escribe Nina Kandinsky a Galka: "Mi marido dice «isólo un gran artista puede pintar así!», finalmente todos se acordarán de Jawlensky (quiero decir: el público). Este es el verdadero objetivo de la exposición, lo que Kandinsky y Klee pretenden"31. Kandinsky reconoce en 1934 el papel decisivo de Jawlensky en su formación durante los años de Múnich, "yo aprendí mucho de usted y por esto siempre le estaré agradecido. No me interesaba tanto la "cabeza" como el contexto orgánico, la unidad de la forma que existe solamente en la síntesis" 32 . En los años 30 se consolida también la amistad con "su querido hermano azul", Feininger, que en una carta le transmite su estima: "has sido una importante referencia en mi recorrido artístico a lo largo de décadas. Representas para mí el ideal de un artista que ha logrado el punto más alto de transfiguración y pureza espiritual" 33 .

\section{Series antecedentes. El retrato como paisaje interior}

En 1917 Jawlensky se instala en Zúrich. En una carta a su hermano Dimitry escribe: "Ahora pinto principalmente rostros y paisajes, la visión de los rostros y de los colores me domina día y noche. Y esta visión espiritual es mi mundo místico" ${ }^{34}$. En este

26 Esta relación de amistad y negocios se ve parcialmente puesta en peligro por el episodio de "presunto robo" de obras de Jawlensky que Scheyer vende sin permiso escrito del artista. Es probable que ella pidiera el permiso para vender las piezas y que dicho permiso nunca llegara. Se trataría sólo de un "malentendido" como zanjará después el artista, aunque con demasiado retraso. Sea como fuere, la credibilidad de Scheyer como vendedora se ve dañada en Europa, lo que constituye una motivación añadida para mudarse a EEUU.

27 Sin embargo, recordamos que la primera aparición de la obra de Jawlensky en Estados Unidos es de 1924 en la galería de la Société Anonyme.

28 En ruso "grajilla", apodo que le atribuye Jawlensky después de un sueño que el artista tuvo en los años veinte en el que su amiga se manifestaba con las formas de un pájaro con un gran pico.

29 ENDICOTT BARNETT, Vivian, "The founding of the Blue Four and their Presentation in New York in 1924-1925", en The blue four. Feininger, Jawlensky, Kandinsky and Klee in the New World, catálogo de la exposición (Berna, Dusseldorf, 1997-98), Cologne, Dumont, 1997, p. 17

30 HELFENSTEIN, Josef, "The most Precious and most personal gifts. Pictures Exchanged between Feininger, Kawlensky, Kandinsky, and Klee”, en The blue four. Feininger, Jawlensky, Kandinsky and Klee in the New World, catálogo de la exposición (Berna, Dusseldorf, 1997-98), Cologne, Dumont, 1997, pp. 79 - 135

31 Ibid., p. 84

32 HAHL-KOCH, Jelena, "La conquista di un linguaggio espressivo autonomo", en CHIAPPINI, Rudy (ed.) (1989), op. cit., p. 50

33 HELFENSTEIN, Josef (1997), op. cit., p. 131

34 JAWLENSKY BIANCONI, ANGELICA (1995), op. cit., p. 23 
periodo emprende las nuevas series de Cabezas místicas y Rostros de santos. Luego, a partir de 1919 y hasta la mitad de los años 30, trabaja casi exclusivamente en la serie de las Cabezas abstractas. En una carta a Verkade de 1938, el artista describe esta etapa: "Durante algunos años pinté las Variaciones y luego necesité encontrar una forma para el rostro, puesto que había comprendido que el gran arte tenía que estar pintado únicamente con un sentimiento religioso. Y esto lo podía trasmitir sólo el rostro humano. Entendía que el artista tiene que decir en su arte, a través de formas y colores, lo que de divino se encuentra en él. Por lo tanto, una obra de arte es Dios visible y el arte es ansia de Dios. Pinté rostros durante muchos años. Estaba sentado en mi estudio y pintaba, y la naturaleza ya no me era necesaria como inspiradora. Era suficiente ahondar en las profundidades de mí mismo, rezando y preparando mi alma en un estado religioso" 35 . La divinidad del rostro arraiga en el vultus, el «yo quiero» y no en la facies, la «apariencia externa». En estas series Jawlensky materializa, por medio de la pintura, su ansia de Dios. Oraciones y repeticiones de un ritual propedéutico a la comunicación divina, para regenerar el deseo de Dios, repetir y repetir, para meditar. Frank E. Washburn Freund comenta en la revista Der Ciceron que "las recientes cabezas de Buda por Jawlensky, cada vez más espirituales, se imprimen para siempre en la memoria, exactamente como las palabras de un Iluminado" 36 . Efectivamente, lo que Jawlensky presenta al público son ejercicios de meditación, etapas de su camino espiritual.

Un episodio juvenil nos acerca a su idea de arte empapada de misticismo, "nos llevaron a ver un famoso icono de una milagrosa Virgen. Este icono tenía tres mantos preciosos, uno dorado, otro de colores y otro de perlas y diamantes. Cuando llegamos, el cuadro estaba escondido tras una cortina dorada. En el suelo yacían tendidos campesinos y campesinas como crucifijos, con los brazos abiertos. Había un gran silencio. De repente, fuertes trompetas quebraron el silencio. Me asusté mucho y vi cómo la cortina se levantaba y aparecía la Virgen con hábito dorado" ${ }^{37}$. En otro momento, recuerda la visita diaria a la Galería Tretjakow, "era para mí un gran acontecimiento, una misa. Estaba como en un templo" 38 . Más allá de la importancia de los iconos rusos en su pintura, de la que hablaremos más adelante, detengámonos ahora en el episodio del desvelo del icono. El artista observa el ritual sagrado, los fieles postrados, el olor a incienso, la musicalidad de aquel "gran silencio" y demás elementos escenográficos con la participación propia de un joven excitado por este ambiente. No sorprende entonces que el descubrimiento del icono y la aparición de la "Virgen con hábito dorado" se convierta en un recuerdo indeleble, la primera aproximación a lo trascendente a través de un ritual pormenorizado que embriaga los sentidos.

Escribe Rudy Chiappini: "El motivo del rostro, despejado de todo detalle como una continua proclamación de fe, se ensalza a icono de Cristo y le reconduce en los cauces de la tradición popular y el misticismo ruso que sitúan el camino de la reden-

35 JAWLENSKY, Alexej von (1991), op. cit., p. 34

36 ENDICOTT BARNETT, Vivian (1997), op. cit., p. 26

37 JAWLENSKY, Alexej von (1991), op. cit., p. 25

38 Ibid., p. 26 
ción en la imagen divina" ${ }^{39}$. Las series de rostros marcan su personal recorrido hacia lo trascendental. Completa una serie como si de un rosario se tratara, para luego dedicarse a otra y otra; repite para meditar. Las Cabezas Místicas están pintadas sobre cartón, siempre del mismo tamaño. Son retratos femeninos donde aparece sólo la cara y el cuello, raramente los hombros. Presentan formas estilizadas, la nariz se reduce a una "L", la boca se sugiere con una o dos líneas horizontales y el cuello con dos líneas verticales y paralelas. Los ojos, perfilados de negro con la pupila oscura, desprenden una atracción magnética. El rostro ocupa casi todo el cuadro, las líneas comienzan a trazarse con lápiz. Los colores, como en las Variaciones, están dispuestos por capas ligeras en zonas yuxtapuestas. Se volcará en esta serie con intensidad y obsesión hasta 1921, aunque la mayoría de las piezas se fechen entre 1917 y 1918.

El pasaje de una serie a otra ocurre bien por el agotamiento del tema, como es el caso de las Variaciones, o bien cuando un problema formal se metamorfosea en una síntesis ulterior ${ }^{40}$, como el paso de las Cabezas místicas a los Rostros de santos. Las distintas series también coexisten. Por ejemplo, en 1920 pinta un centenar de Rostros de santos, un número menor de Cabezas abstractas y también unas ochenta Variaciones $^{41}$.

Los Rostros de santos son asexuados. El óvalo ocupa ahora toda la superficie y los contornos están perfilados ligeramente a lápiz. Los grandes ojos permanecen abiertos, mientras la nariz está trazada por delgadas líneas ortogonales. Domina una simetría que las acerca a los iconos y no sorprende que aparezca una mancha de luz, el "tercer ojo" de la sabiduría, en el medio de la frente. En las Cabezas abstractas los ojos cerrados añaden un ulterior elemento de impersonalidad ${ }^{42}$. Dirigen su mirada hacia dentro, rechazan una comunicación directa con el espectador. Ojos cerrados para ver sin necesidad de mirar. Y además ¿para qué seguir mirando hacia una Europa destruida por la guerra y empantanada en un desastre económico?

Las Cabezas abstractas suponen un peldaño más para lograr "cuanto de divino haya en el rostro humano"43. El óvalo tiende a superar los límites del cuadro. Según Jawlensky, una cabeza abstracta "no es un rostro, sino lo que se cierra debajo, que se abre hacia arriba y que se encuentra en el medio" ${ }^{4}$. Se trata de un lugar de encuentro y dispersión, un campo de fuerzas, donde lo terrenal y lo divino se acercan, acaso se rozan. Los delicados tonos pastel se aplican con salpicaduras, casi estampando el color en el cartón o en el papel con textura de lino. Como algunos Rostros de santos, ahora de manera más sistemática, las Cabezas abstractas presentan una visión frontal con una marcada simetría, un equilibrio que transmite "seguridad y sosiego" 45 . Res-

39 CHIAPPINI, Rudy, “Un audace cromatismo per sfidare le tenebre”, en CHIAPPINI, Rudy (ed.) (1989), op. cit, p. 24

40 "Sistematización estructural" según Coplans. COPLANS, John (1968), op. cit., p. 32

41 JAWLENSKY, Angelica, "Il cammino verso 1'atrazione", en CHIAPPINI, Rudy (ed.) (1989), op. cit, p. 140

42 COPLANS, John (1968), op. cit., p. 32

43 JAWLENSKY, Angélica (1992), op. cit., p. 23

44 JAWLENSKY BIANCONI, Angélica (1995), op. cit., p. 25

45 JAWLENSKY, Angélica (1992), op. cit., p. 25 
pecto a los años en Wiesbaden ${ }^{46}$, anota: "pinté durante algunos años sólo mis grandes Cabezas abstractas. Estaba concentrado en estas obras y quería alcanzar un contenido espiritual completo y perfecto" ${ }^{47}$. Una vez encontrada una estructura formal, con gran atención la repite en variaciones que liberan su pasión por el color. Refiriéndose con toda probabilidad a esta serie, en una carta a Emmy Scheyer del 22 de diciembre de 1919, comenta el juicio de Klee según el cual "son demasiado pensadas", crítica que Jawlensky encuentra "injusta" 48 y es fruto quizás del carácter marcadamente constructivo de las Cabezas abstractas ${ }^{49}$, con su rigurosa disposición formal. Por otro lado, en una reseña de 1921, W. A. Luz, escribe que "estas obras piden ser admiradas como los retratos de los santos en los relicarios de los antiguos trípticos". Por su parte, Wil Grohmann en 1925 señala que "no existe nadie, a excepción de Jawlensky, que sea capaz de extraer así del rostro humano tantas posibilidades de representación" ${ }^{50}$. Se trata de una serialidad extensa, una voluntad de conocimiento que ha encontrado en el rostro su base antropocéntrica dirigida hacia lo divino ${ }^{51}$.

En 1921, Jawlensky confiesa a Emmy Scheyer: "He trabajado muchísimo y me parece haber entendido sólo ahora cómo tienen que pintarse mis cabezas. Ahora pinto muy despacio y creo que mis cabezas han mejorado un poco, están más logradas" ${ }^{52}$. Una apuesta para la lentitud del gesto que se inscribe dentro del rito de su pintura. Una vez lograda una gran soltura, ralentiza la ejecución, para no perder la conciencia de los movimientos y del ritmo de la realización. Durante las letanías, la costumbre difumina la comprensión de las palabras que se convierten en un mero sonido, carente de significado. Esto se desmorona durante el recital automático y es frecuente caer en una repetición mecánica, aunque, sin duda, reconfortante. Ralentizar el proceso conlleva experimentarlo a un nivel más hondo; una atención consciente conduce ahí donde lo corporal se asoma en lo espiritual. "En verdad, la atención es la senda hacia la Inmortalidad; la negligencia nos conduce a la muerte. Los que son atentos jamás perecen, pero los que son negligentes es como si ya estuviesen muertos" ${ }^{53}$.

\footnotetext{
46 Donde se había mudado desde Ascona, en seguida al éxito comercial de una exposición individual

47 JAWLENSKY, Alexej von (1991), op. cit., p. 33

48 JAWLENSKY, Angélica (1992), op. cit., p. 23

49 Según Werner Haftmann: "La rigurosa geometría de sus rostros de los años 20 muestra los reflejos del Contructivismo librado de las influencias del Cubismo y del De Stijl. Sin embargo, Jawlensky desplaza el elemento que Mondrian perseguía en el plano intelectual dentro una dimensión místico-religiosa. En el contraste fundamental entre horizontal y vertical que Mondrian asume como el símbolo principal del equilibrio universal, Jawlensky reconoce el símbolo cristiano del equilibrio religioso - la Cruz". HAFTMANN, Werner, citado en JAWLENSKY, Angélica (1993), op. cit., p. 16

50 JAWLENSKY, Angélica (1992), op. cit., pp. 26-27

51 CHIAPPINI, Rudy (1989), op. cit., p. 24

52 JAWLENSKY, Angélica (1989), op. cit., p. 144

53 EL DHAMMAPADA. El Sendero de la Realización Interior, Editorial Hastinapura, Buenos Aires, 2004, p. 25
} 


\section{Artritis deformante y degeneración política}

En la década de los 20 comienza un periodo complicado para el artista, económica y físicamente. El exceso de producción y el aislamiento contribuyen a sus escasos éxitos comerciales. Sin embargo la admiración de otros artistas es incondicional. Recuerda Nina Kandinsky que Wassily "solía recomendar a Jawlensky a galerías y museos. A menudo Kandinsky decía: «tienes que incluir definitivamente a Jawlensky en esta exposición». Estaba totalmente convencido de la importancia de Jawlensky" ${ }^{54}$. Entre 1926 y 1927 el artista empieza a sufrir los síntomas de una enfermedad que le acompañará hasta la muerte. Intentará tratamientos caros y estrafalarios, definitivamente inútiles. Hacia finales de los años 20, Jawlensky depende para sustentarse de las ventas de Scheyer y de una pequeña renta que recibe de la "Sociedad Jawlensky", una asociación fundada por la coleccionista Hanna Bekker von Rath, de la que recibe una suma mensual a cambio de obras.

La situación en la que pinta las Meditaciones es dramática por su enfermedad y pobreza. Empeora aún más cuando el régimen nazi tacha su obra de "degenerada". En 1937 confiscan 72 obras suyas de los museos alemanes. Reflexiona consternado por esta decisión: "No se me permite exponer mis obras aquí. ¿Por qué no? Mi arte no es, de ninguna manera, subversiva. Y tampoco soy un bolchevique, ni en mi arte ni en mi vida. Mi arte no es otra cosa que meditación, u oración en color. Y no es posible que dañe a nadie" ${ }^{55}$. En la tristemente célebre Entartete Kunst en Múnich se expondrán cuatro obras de Jawlensky.

\section{Las Meditaciones}

"Todo retrato se refiere a la muerte, lo que equivale a afirmar que supone una conciencia activa de la trascendencia. ¿Cómo percibir la unicidad del individuo, o dicho de otro modo, cómo no considerarlo un absoluto, el cual, tanto si es rechazado como un simple espejismo metafísico, o apresado como una esperanza, obliga a tomar distancias con respecto al encadenamiento de causas y efectos que constituye la simple naturaleza?" 56 . Observar al retratado supone constatar tanto su precariedad como la propia, a saber, emprender un camino de liberación hacia la trascendencia. Recorrido que impone, evidentemente, un progresivo desprenderse del tiempo terrenal, su "encadenamiento de causas y efectos", para expandirlo a través de la repetición de rituales siempre iguales y siempre diversos. Una abstracción meditativa por los senderos del conocimiento espiritual que, en el caso que aquí nos atañe, se materializa en una serie pictórica.

Jawlensky se centra en el ser humano despojado de toda transitoriedad, todos y nadie. La serie, como conjunto de otras posibilidades, empuja a superar el horror del tiempo encadenado, el espectro de la muerte definitiva y la fragmentación del tiem-

54 HELFENSTEIN, Josef (1997), op. cit., p. 82

55 JAWLENSKY BIANCONI, Angélica (1995), op. cit., p. 29

56 BONNEFOY, Yves (2003), op. cit., p. 140 
po en el trabajo asalariado. Estas Meditaciones nos amparan de una tiranía que sólo sabe enfrentarse al tiempo midiéndolo. En 1938, en una carta a Verkade, Jawlensky describe la situación en la que se gestan: "Así los años transcurrían con tanto trabajo. Luego me puse enfermo y casi no lograba pintar, mis manos se volvían cada vez más rígidas. Ya no podía sostener el pincel con una mano y tenía que utilizar las dos para conseguirlo, siempre con gran dolor. El formato que utilizaba se hizo muy pequeño y tenía que encontrar también una nueva técnica. Durante tres años pinté estas pequeñas cabezas abstractas como poseído" ${ }^{57}$. Las Meditaciones son su última serie, realizada hasta 1938, año en el que deja de pintar ${ }^{58}$. Tiene que hacerse atar el pincel entre las dos manos enrigidecidas por la enfermedad. La pincelada es ancha y los colores más obscuros que nunca. Desaparece el óvalo de la cabeza, amplios trazos verticales ocupan toda la superficie. El rostro se reduce a una cruz, pinceladas horizontales para los ojos y la boca, verticales para la nariz ${ }^{59}$. Se trata de oraciones sin palabras, rituales místicos ${ }^{60}$. La entera composición forma una retícula fija que, diversamente de las de Mondrian, permanece casi inalterada en toda la serie, obra tras obra.

Al final de su vida, el artista, consciente del propio aislamiento, pinta sólo para sí mismo. Realiza sus series con la total certidumbre de que no podrá vender ni exponer lo que crea. Pese a esto, su producción aumenta, "los cuadros son todavía más hondos y espirituales, comunican sólo a través de colores" ${ }^{61}$, lo que nos lleva a considerar las Meditaciones como una necesidad vital. "Una terapia para la supervivencia" ${ }^{2}$, se ha escrito. En 1934 confiesa a Kandinsky: "En este periodo estoy pintando sólo para mí mismo, es la única posibilidad que tengo ahora, a nadie le sirve, con la excepción, como mucho, de algunos amigos. [..., pinto] a menudo con los ojos llenos de lágrimas de sufrimiento. Al mismo tiempo, trabajo todos los días, porque esto es mi gran gozo" ${ }^{63}$.

\section{Oraciones y alma}

El artista habla continuamente de "éxtasis interior" ${ }^{64}$ y de "misterio de la creación" ${ }^{65}$; ya hemos visto cómo la componente mística es fundamental para entender su arte. Jawlensky, después de su huida de Múnich, se cierra en sí mismo y quizá la religión le

\footnotetext{
57 JAWLENSKY, Alexej von (1991), op. cit., p. 34

58 Según Tayfun Belgin, Jawlensky pintará más de 1600 Meditaciones. BELGIN, Tayfun (2000), op. cit., p. 180

59 Esta misma técnica aparece en otra serie de bodegones de este periodo.

60 Según Zweite: "Respecto a su aura espiritual, los iconos que Jawlensky pinta hacia el final de su vida están evidentemente influidos por el impulso religioso subyacente a las actividades del Jinete Azul", en ZWEITE, Armin (1989), op. cit., p. 53

61 JAWLENSKY, Alexej von (1991), op. cit., p. 33

62 LEINZ, Gottlieb, "L'affermarsi della componente mistica", en CHIAPPINI, Rudy (ed.) (1989), op. cit, p. 180

63 HELFENSTEIN, Josef (1997), op. cit., p. 134

64 JAWLENSKY, Angelica (1989), op. cit, p. 102

65 MOCHON, Anne, "Emmy Scheyer e i Quattro Blu", en CHIAPPINI, Rudy CHIAPPINI, Rudy (ed.) (1989), op. cit., p. 154
} 
ofrezca cierta consolación. No cabe reducir estas obras a una dimensión meramente consolatoria, es más correcto enmarcarlas en el complejo campo de la meditación trascendental. En Múnich se interesa por temas esotéricos, por la antroposofía y conoce a Rudolf Steiner ${ }^{66}$. A partir de 1916, lee textos sobre el budismo y los yoguis hindúes. En el Dhammapada está escrito: "A través de la meditación, de la perseverancia, y con una infatigable energía, los sabios logran la liberación de las ataduras mundanas" ${ }^{\prime \prime}$. Según la tradición mística india, la ascesis y la meditación tienen como finalidad guarir al ser humano del sufrimiento del horror del tiempo, el sufrimiento causado por el ciclo de nacimientos y muertes. Esto es lo que Jawlensky parece intentar con su pintura. En 1936 escribirá a Nolde que está pintando "con ardor, como una oración" ${ }^{68}$. Su obra forma parte de aquella variable mística del expresionismo ${ }^{69}$, sin olvidar el conocido interés de Kandinsky y Mondrian por estos temas ${ }^{70}$, o el enfoque espiritual del último Georges Rouault. Según Franz Marc "el espíritu derriba los muros del castillo" 71 y para Kandinsky "el nacimiento de una obra de arte tiene una naturaleza cósmica. El creador de la obra es el espíritu"72. Afirmaciones suficientes para evidenciar cómo la investigación de Jawlensky no está sola en el contexto europeo. Pero asombra su voluntad por limitar el campo de su acometida. Considera sus obras como oraciones, rituales para meditar y aislarse del mundo para arribar a un lugar donde el espíritu encuentre reparo. A lo largo de su trayecto artístico va afianzado un proceso de espiritualización, sus cuadros se pueblan de instancias metafísicas, místicas y poéticas. Uno de los métodos que usa Jawlensky para representar lo no representable es la serie, la repetición como mantra, camino a lo trascendental.

\section{John Cage}

Un joven y talentoso músico adquiere en 1935 una Meditación al precio mínimo de 25 dólares. Con gran emoción, escribe una breve nota, en alemán, al artista: "Estoy encantado de haber comprado una de tus obras. Ahora está dentro de mí. Yo escribo música, tú eres mi maestro"73. Unos años después, en 1938, empieza a barajar con

66 En una conferencia que Steiner pronuncia en Zürich en 1918, cuando Jawlensky vivía en esta ciudad, podemos hallar ideas y sentimientos que nuestro pintor sin duda compartía: "Ciencia espiritual para el espíritu, libertad en la vida religiosa para el alma y fraternidad para la vida corporal, esto resuena como música cósmica a través de la labor que realizan los Ángeles en los cuerpos astrales del hombre. Lo único que necesitamos es elevar nuestras conciencias a un nivel diferente ya que, entonces, nos sentiremos transportados hacia esta maravillosa condición creada por los Ángeles en el cuerpo astral del ser humano. Estamos viviendo en la época del Alma espiritual". STEINER, Rudolf, Los Ángeles y el cuerpo astral, Barcelona, Ediciones Obelisco, 2004, p. 26

67 EL DHAMMAPADA, op. cit., p. 26

68 LEINZ, Gottlieb (1989), op. cit, p. 204

69 "La época de la religión” la define en 1922 Kirchner. Ibid., p. 182

70 RINGBOM, Sixten, Art in "The Epoch of the Great Spiritual": Occult elements in the early theory of Abstract Painting”, en Journal of the Warburg and Courtauld Institutes, 29, 1966, pp. 368-418

71 ZWEITE, Armin (1989), op.cit., 1989, p. 39

72 Ibid., p. 41

73 MÜLLER, Maria, “It's a long, long road. John Cage and Galka Scheyer”, en The blue four. Feininger, Jawlensky, Kandinsky and Klee in the New World, op.cit., p. 273 
Emily Scheyer la posibilidad de realizar exposiciones de los "Cuatros Azules" en Seattle en la Cornish School donde enseña. Y efectivamente, realizará, entre febrero y marzo, exposiciones individuales de Klee, Kandinsky y Jawlensky. La exposición incluye veinte obras, principalmente Meditaciones. Contrariamente a sus expectativas no logra venta alguna, "pese a que las exposiciones despertaron un interés sobrecogedor. Esto a menudo me pone triste. Creo que va a ser un largo, largo camino"74. Los únicos compradores son, de hecho, Xenia y John Cage que adquieren dos obras de Jawlensky por sólo 30 dólares. Aunque Cage reiteradamente demuestra un gran entusiasmo hacia las acuarelas de Klee y Kandisnky, finalmente se decanta por las obras de Jawlensky.

Por aquel entonces está estudiando con Arnold Schönberg. Según el músico austriaco la variación es una forma extrema de repetición. No será este un detalle secundario, quizá Cage reconoce y aprecia la última y radical serie de Jawlensky, no sólo en términos plásticos, sino también conceptuales ${ }^{75}$, como método de composición. "El concepto de música dodecafónica corresponde a la idea de variación continua, a la idea de Schönberg que en el curso de su desarrollo las variaciones se repiten" Puede que el compositor vislumbre una afinidad entre las series del rostro humano del pintor y su idea de variación musical; "yo escribo música, tú eres mi maestro"77.

\section{Iconos y tradición}

Alrededor de 1900 en su Rusia, se produce un renovado entusiasmo hacia el arte de los iconos debido a que finalmente se pueden contemplar en todo su esplendor gracias a modernas técnicas de limpieza. Por primera vez, se coleccionan, exponen y se reconocen como una fuente cardinal de la tradición nacional. Artistas como Kuzma Petrov-Vodkin, Pavel Kuznetsov, Mikhail Larionov, Natalia Goncharova, Vladimir Tatlin, Kazimir Malevich, Alexandre Shevchenko y Alexej Grishchenco llegarán a dominar este legado pictórico. Un interés que excederá los confines rusos. En 1911 Henri Matisse viaja a Rusia invitado por un coleccionista y anota: "ayer he visitado una colección de antiguos iconos rusos. Es un arte verdaderamente magnifico. Estoy enamorado de su simplicidad móvil que me resulta más cercana y querida que Fra Angelico. En estos iconos el espíritu de los pintores que los realizaron se abre como una flor mística. Y de ellos deberíamos aprender cómo entender el arte"78. Matisse considera los iconos como materialización del espíritu de los pintores que los realizaron y subraya el misticismo de estas obras. Se trata de un comentario revelador tanto

$74 \quad$ Ibid., p. 277

75 Una posible influencia de sus series en la serialidad americana a partir de 1966 ha sido estudiada, entre otros, por Katherina Schmidt en el catálogo de la exposición dedicada al artista (Múnich/Baden-Baden, 1983). Tampoco hay que descartar una posible influencia, vía Cage, de las conferencias y exposiciones de Galka Scheyer, en pintores seriales como Rothko, Newman y Reinhardt.

76 MÜLLER, Maria (1997), op. cit., pp. 277-278

77 “I write music, you're my teacher". MÜLLER, Maria (1997), op. cit., p. 273

78 SPIRA, Andrew, The Avant-Garde Icon. Russian Avant-Garde and the icon painting tradicion, Londres, Lund Humphries, 2008, p. 55 
para entender el sentimiento de la época como para enmarcar correctamente la series de Jawlensky. Sugerente como la apreciación de Matisse y aún más importante con respecto a nuestro pintor, es lo que escribe Larionov en 1920 en su ensayo sobre los iconos: "Existen dos principios artísticos. El primero: copiar a la naturaleza a partir de los conocimientos adquiridos y usar formas naturalistas de diversas maneras en la composición. [...] El segundo: estudiar la vida en sí misma, sin preocuparse de las manifestaciones del mundo externo y, basándose en estas formas siempre cambiantes, traducir el aspecto más expresivo del objeto o de la situación... Los pintores de iconos se inclinaban por este segundo principio y tendían fuertemente hacia la abstracción. Esta abstracción se manifiesta en el uso de esquemas y fórmulas relacionadas con un estilo predeterminado a través del cual ellos expresaban su sentido místico y abstracto de la existencia... Es a través de los matices del color y la sutileza de las formas que el estado místico y religioso que experimentamos frente a los iconos se manifiesta... Es un tipo de realismo espiritual. Rostros idealizados, pliegues convencionales, perfección esquemática de los paños: ninguno de estos existe en la vida ordinaria... Crees realmente que se refieren a otra vida" 79 . La esencia del objeto a pintar no reside en su materialidad, sino en la estructura dinámica de su campo de fuerzas. Esta teoría de los iconos bien se adapta a lo que hemos visto respecto a Jawlensky, moderno pintor del alma. ¿Rostros de santos, Cabezas abstractas y Meditaciones no son acaso la representación de lo mismo siempre cambiante y no se refieren a otra vida? Su acometimiento serial le lleva a realizar innumerables variaciones del esquema formal de la cruz. Desborda los límites de la individualidad y aspira a representar algo extraordinario; según el artista la obra de arte es un mundo, no la imitación del mundo y su arte pretende visualizar lo invisible.

Pavel Florensky ejemplifica el poder de los iconos paragonándolo al campo de fuerzas de un imán, no basta representar el metal para expresar sus propiedades. Lo que importa son sus calidades físicas, pero invisibles. La serialidad encarna las reiteradas tentativas de representar este campo de fuerzas. Fuerzas múltiples que reclaman igualmente múltiples representaciones de lo invisible. Contemporáneamente a Larionov, Florensky estudia el lenguaje de los iconos y explica cómo su técnica ${ }^{80}$ satisface una instancia espiritual, "las formas visibles están creadas por aquellas líneas invisibles y caminos de la luz divina" ${ }^{81}$. Los colores puros, la simplificación de las formas, la exagerada verticalidad y la ausencia de profundidad son típicas tanto de los iconos como de las Meditaciones. Ambos pretenden transmitir la impresión, o por lo menos, el halo de otro mundo; excitan a renunciar a la realidad transeúnte para alcanzar, a través de una incesante oración, la conexión con lo divino. Ciertamente hay infinitas vías para alcanzarla y largo es el camino hacia la luz divina.

Los rostros de las Meditaciones son despersonalizados, "el rostro para mí no es un rostro, sino más bien el cosmos en su integridad. En el rostro se manifiesta el cosmos entero" 82 . El parecido no es importante para el pintor, es suficiente indicar algo que

79 SPIRA, Andrew (2008), op. cit., pp. 59 - 60

80 FLORENSKY, Pavel, La perspectiva invertida, Madrid, Siruela, 2005

81 SPIRA, Andrew (2008), op. cit., p. 65

82 JAWLENSKY, Alexej von, citado en JAWLENSKY, Angélica (1992), op. cit., p. 26 
se escapa de la condición humana. Jawlensky anhela a que el rostro eterno, que se esconde detrás de los caracteres móviles, aflore.

En una carta de 1939, afirma que "cada artista trabaja dentro de una tradición. [...] Yo nací ruso. Mi alma rusa siempre estuvo próxima al arte ruso antiguo, los iconos, el arte bizantino, los mosaicos de Rávena, Venecia, Roma y el arte románico. Todas estas artes pusieron siempre mi alma en un estado de sagrada vibración, puesto que yo sentía que en ellas latía un profundo lenguaje espiritual. Este arte fue mi tradición"83. Las Meditaciones son deslizamientos y desplazamientos de una forma que el artista asume como originaría. En una perspectiva serial, el acto artístico puede continuar al infinito. El gran problema de la escasez de tiempo a través de la serialidad se convierte en una excedencia de tiempo, en un infinito exceso de tiempo. Si los rituales son instrumentos para amparar a los seres humanos del horror del tiempo, ordenar el caos, la serie proporciona un superávit. Repite los gestos para caricaturizar la absurda lógica productiva que fantasea salvarse del tiempo midiéndolo y dividiéndolo en partes iguales. Con la serialidad el tiempo estalla en centenares de pedazos de tiempos heterogéneos. Un reloj roto flota en un charco después del paso de la serie.

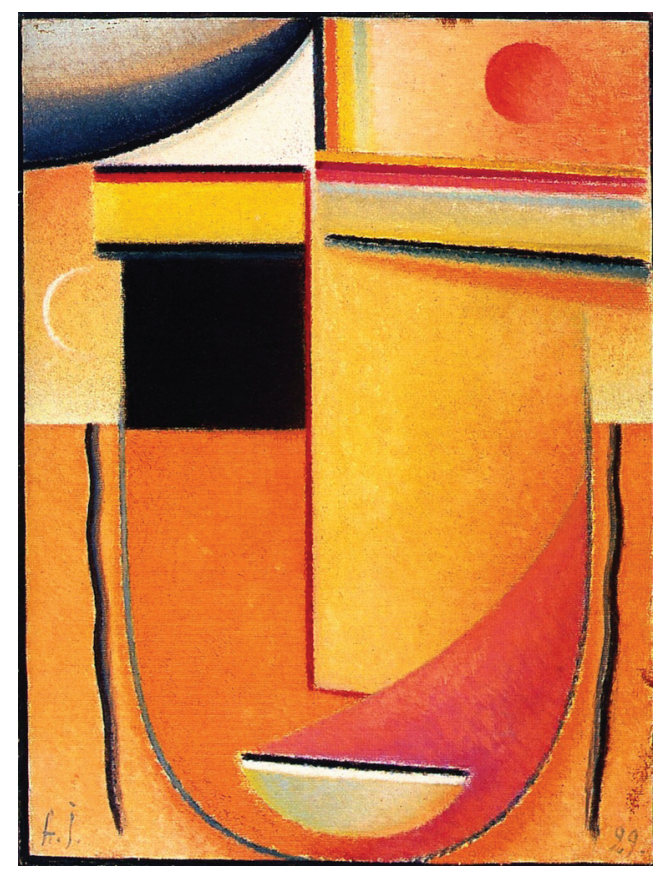

Fig. 1. Alexej von Jawlensky, Cabeza abstracta, luz cálida I, 1929, óleo sobre cartón, $42.8 \times 33 \mathrm{~cm}$, colección privada.

83 JAWLENSKY, Alexej von, citado en JAWLENSKY, Angélica (1992), op. cit., p. 13 


\section{Conclusiones}

"La medida y la banalidad se han apoderado del mundo, relojes cada vez más precisos han sustituido a las viejas clepsidras aún llenas de un sentido funerario. Y la guadaña del viejo implacable ha acabado como todos los demás espectros. La tierra ha sido vaciada de lo que hacía la noche temblorosa la peor desgracia y la guerra misma no puede ya más modificar una cómoda representación. El resultado es que la codicia humana ya no se dirige hacia límites poderosos y majestuosos: por el contrario, aspira a todo lo que la libera de la tranquilidad establecida" ${ }^{4}$. Esto es lo que opina Bataille sobre el horror del tiempo y la urgencia contemporánea. Jawlensky realiza estas últimas oraciones con una dedicación monástica. Cada gesto del pulso acorde con el latido interior. Un ritmo consciente domina sus obras seriales. Pretende encontrar refugio en su ritmo vital, escapando del tiempo exterior ${ }^{85}$, que lejos de ser un límite majestuoso es el tiempo del trabajo necesario. Es el horror impuesto a través de su símbolo: el reloj. Como aquel que marca los pasos de los obreros en Metropolis (1926) de Fritz Lang. En un anuncio publicitario de 1923 realizado por Rodchenko con un texto de Majakovsky, vemos que las prótesis del ser humano son relojes. "Medidores precisos y exactos, ¡los vais a necesitar!", sin duda para medir el tiempo de la codicia y de la explotación. Acierta Bataille cuando advierte que a la caída del ser humano, sin base ni cabeza, han añadido el reloj. Vuelve el terror del tiempo del que los antiguos habían aprendido a defenderse.

El ser acéfalo, condenado ahora a sufrir el paso constante del tiempo calculado en moneda, es el destinatario de las últimas Meditaciones de Jawlensky, que pretende devolverle la cabeza perdida, porque si Dios ha muerto, no parece digno remplazarlo por un reloj de pulsera.

\footnotetext{
84 BATAILLE, Georges, "L'obelisco", en BATAILLE, Georges, Il labirinto, Milán, SE, 2003, p. 42

85 "Los objetos que la regla monacal asignaba para la meditación a los hermanos tenían la tarea de prevenirlos contra el mundo y todo su trajín". BENJAMIN, Walter, "Sobre el concepto de Historia", en BENJAMIN, Walter, Obras. Libro I. Vol.2, Madrid, Abada Editores, 2008, p. 311
} 